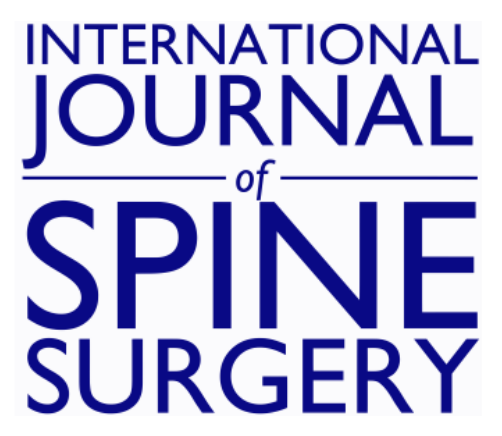

\title{
Prognostic Factors Related to Motion Dynamics Following Cervical Arthroplasty With a Bryan Disc: Average 2-Year Follow-Up
}

Kyeong-Sik Ryu, Han-Yong Heo, Sung-Jae Lee, Kwon-Yong Lee and Chun-Kun Park

Int J Spine Surg 2008, 2 (2) 86-91

doi: https://doi.org/10.1016/SASJ-2007-0117-RR

http://ijssurgery.com/content/2/2/86

This information is current as of April 26, 2023.

Email Alerts Receive free email-alerts when new articles cite this article. Sign up at:

http://ijssurgery.com/alerts

The International Journal of Spine Surgery

2397 Waterbury Circle, Suite 1,

Aurora, IL 60504, Phone: +1-630-375-1432 


\title{
Prognostic Factors Related to Motion Dynamics Following Cervical Arthroplasty With a Bryan Disc: Average 2-Year Follow-Up
}

\author{
Kyeong-Sik Ryu, MD, ${ }^{a}$ Han-Yong Heo, MD, ${ }^{a}$ Sung-Jae Lee, PhD, ${ }^{b}$ \\ Kwon-Yong Lee, PhD, ${ }^{c}$ and Chun-Kun Park, $M D^{a}$
}

\begin{abstract}
Background

This is a retrospective study to assess the prognostic factors influencing the postoperative motion dynamics and clinical outcome following cervical arthroplasty with a Bryan disc.

\section{Methods}

Twenty-seven patients (30 levels) consecutively underwent cervical arthroplasty using a Bryan disc (Medtronic Sofamor Danek, Memphis, Tennessee). Motion dynamics and clinical outcome (visual analogue score (VAS) and neck disability index (NDI) score) were examined preoperatively and at 1 month, 1 year, and final follow-up (average: 25 months). The prognostic factors influencing clinical outcome and postoperative motion dynamics were assessed.

\section{Results}

At last follow-up, mean VAS and NDI scores were significantly decreased from $8.33 \pm 1.52$ to $1.10 \pm 0.99(P=.001)$ and from $25.0 \pm 15.9$ to $9.2 \pm 5.9(P=.001)$, respectively. In a comparative study of pre- and postoperative motion changes at operated segments, mean segmental range of motion (ROM) increased from $6.96^{\circ} \pm 2.03^{\circ}$ to $8.93^{\circ} \pm 3.53^{\circ}(P=.014)$, and mean segmental angle decreased from $2.85^{\circ} \pm 3.27^{\circ}$ to $1.21^{\circ} \pm 5.93^{\circ}(P=.126)$. Mean global angle increased significantly from $14.54^{\circ} \pm 10.32^{\circ}$ to $18.36^{\circ} \pm 11.10^{\circ}(P=.003)$, and $\mathrm{ROM}$ increased non-significantly from $40.25^{\circ} \pm 13.51^{\circ}$ to $41.56^{\circ} \pm 12.53^{\circ}(P=.654)$. At upper and lower segments, ROMs did not change significantly postoperatively. The heights of functional segment units showed no change postoperatively $(3.51 \pm 0.21$ to $3.49 \pm 0.22, P=.701)$. No significant relationships were found between VAS and NDI improvement and changes in ROMs or segmental angles at last follow-up. Statistically, the postoperative functional segment unit (FSU) ROM decreased as the age of the patients increased (Spearman $r=0.391, P=.048$ ). The gender and preoperative segmental ROM did not influence FSU ROM.
\end{abstract}

\section{Conclusions}

Our results demonstrate that cervical arthroplasty with the Bryan disc for the treatment of cervical degenerative provides a good clinical outcome and preserves motion postoperatively. The age of the patients and the preoperative segmental ROM significantly affect the postoperative FSU ROM. These factors however do not relate to the clinical outcome. The relationship between longterm outcome and these variables should be verified by a larger cohort study.

Key Words: Motion dynamics, cervical arthroplasty, cervical degenerative disease. SAS Journal. Spring 2008;2:86-91. DOI: SASJ-2007-0117-RR

\footnotetext{
${ }^{a}$ Department of Neurosurgery, Kang Nam St. Mary’s Hospital, Catholic University, Seoul, Korea; ${ }^{b}$ Department of Biomedical Engineering, Inje University, Kimhae, Korea; ${ }^{\mathrm{C}}$ Bioengineering Research Center, Sejong University, Korea

Address correspondence to Chun-Kun Park, MD, Department of Neurosurgery, Kang Nam St. Mary’s Hospital, 505 Banpo-Dong, Seocho$\mathrm{Ku}$, Seoul, 137-701, Korea

The authors have no financial interest or other potential conflicts of interest to report in relation to the device used in this study.

This work was supported by grant No. R01-2005-000-10116-0 from the Basic Research Program of the Korea Science \& Engineering Foundation and in part by Synthes Asia Pacific.
}

\section{INTRODUCTION}

Anterior cervical discectomy with fusion (ACDF) is a major surgical modality for the treatment of degenerative cervical spine diseases. However, many reports have shown evidence of the development of junctional degeneration adjacent to fused levels due to increased biomechanical stress..$^{1-5}$ Adjacent segment degeneration (ASD) was observed radiographically in up to $50 \%$ and clinically in up to $15 \%$ of patients who were followed for more than 5 years after fusion surgery. ${ }^{1,3,6}$
Currently, cervical arthroplasty using various implants has been suggested as a substitute for ACDF. The fundamental rationale for cervical arthroplasty is the motion preservation of treated segments, which could reduce ASD.

Although many favorable clinical results have been reported, cervical arthroplasty still demands careful patient selection and good knowledge of spinal functional anatomy and biomechanics. The main concerns are whether disc replacement 
prostheses demonstrate actual motion preservation in vivo and whether they maintain sagittal alignment in the long term.

The purpose of this retrospective study is to quantify radiographically the segmental angle and range of motion (ROM) of a cervical replacement, the Bryan disc (Medtronic Sofamor Danek, Memphis, Tennessee), at the affected and adjacent segments, and to evaluate the relationship between preoperative factors such as the age of the patient and preoperative ROM and postoperative clinical factors such as the clinical outcome and radiographic findings including postoperative $\mathrm{ROM}$ in the patients followed for an average 2 years.

\section{MATERIALS AND METHODS}

From March 2004 to May 2005, 27 patients with degenerative cervical spine disease, including soft and hard disc disease, as confirmed by various radiological studies, consecutively underwent cervical arthroplasty using a one type of disc prosthesis by a single surgeon (C.K.P.) at our institute. There were 16 men and 11 women of ages ranging from 35 to 61 years (mean age: $50.43 \pm 9.43$ ). All patients had a history of failed conservative treatment of at least 3 months in duration. Exclusion criteria included osteoporosis, prior surgery at the treated level, an infectious condition, severe multilevel spondylosis, pregnancy, and neoplastic disease. Following standard anterior cervical discectomy, implantation was performed as described by Goffin et al. ${ }^{7}$ Clinical outcomes were assessed by an independent third party (unaware of relevant patient details) using the visual analogue pain scale (VAS) and neck disability index (NDI) scores. Follow-up intervals ranged from 12 to 32 months (mean: 25 months).

Radiographic images were obtained for all patients preoperatively, at 1 month and 1 year postoperatively, and at final follow-up. Images obtained at each time point consisted of anteroposterior (AP), lateral, flexion, and extension films. Detailed radiographic assessments were performed on digital radiograph images displayed on a PACS (Picture Achieve and Communication System) terminal (Marosis 2003, Marotech, Seoul), and angles were measured using a program in PACS. Angles of functional segment units (FSUs), global angles (from the lower endplate of $\mathrm{C} 2$ to the inferior endplate of C7), and adjacent segment angles were measured. Flexionextension segmental ROM was measured at all affected and adjacent levels. ROMs were determined from differences between flexion and extension angles. Global ROMs and FSU heights (Figure 1) were also measured.

Measurements were performed twice by 2 independent observers (fellow spinal surgeons not involved in the surgeries), and average values were calculated. All radiological values were compared pre- and postoperatively.

Statistically, FSU ROM at the index level was assessed in relation to age, gender, and preoperative ROM. The

\section{Figure 1.}

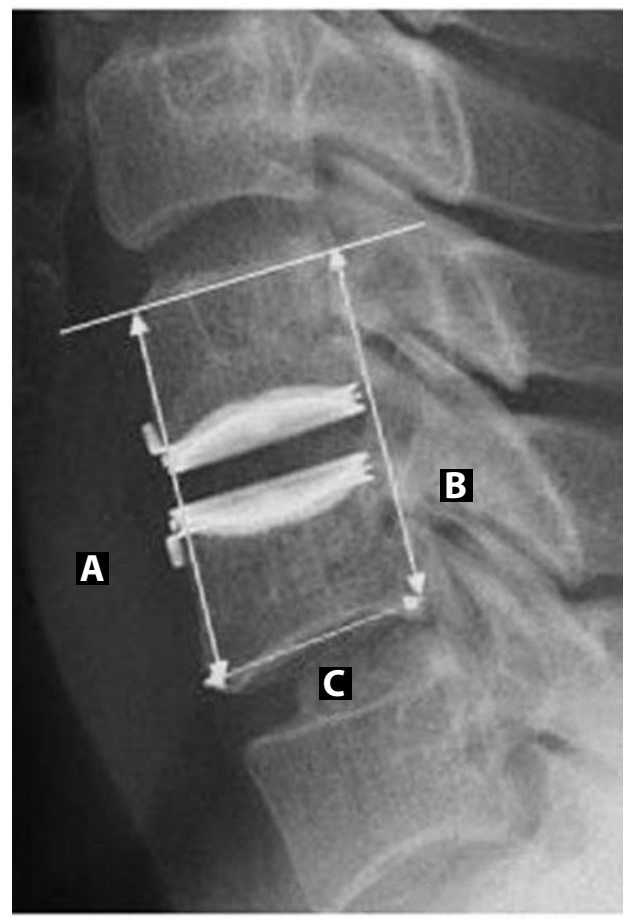

Radiograph showing the method of FSU height measurement. Both anterior and posterior FSU heights were measured pre- and postoperatively. The A and $\mathrm{B}$ represent the anterior and posterior heights between the superior endplate of the rostral vertebra and the lower endplate of the caudal endplate, respectively. Film magnification was adjusted into the value which was obtained by the length of the inferior endplate of the caudal vertebra into the sum of the value $A$ and $B(A+B / C)$.

relationships between FSU ROM and the changes in VAS and NDI scores (ie, differences between preoperative and final follow-up values) were also analyzed. In patients that underwent 2-level surgery, average values were used.

SPSS for Windows (version 11.0.1; SPSS Inc., Chicago, Illinois) was used for the analysis, and results were considered statistically significant at the $P<.05$ level.

\section{RESULTS}

One-level or 2-level operations were performed in 24 and 3 cases, respectively. Overall, a total of 30 segments were operated on: C4-5 in 4 cases, C5-6 in 21 cases, and C6-7 in 5 cases. At final follow-up, mean VAS and NDI scores had significantly decreased from $8.33 \pm 1.52$ to $1.10 \pm 0.99(P$ $=.001)$ and from $50.0 \pm 31.8 \%$ to $18.4 \pm 11.8 \%(P=.001)$, respectively.

The changes in average FSU, adjacent segment, and global angles are shown in Figure 2. FSU angles were significantly reduced from $2.85^{\circ} \pm 3.27^{\circ}$ to $1.03^{\circ} \pm 5.74^{\circ}(P=.012)$ at 1 month postoperatively, and were maintained at final followup. The correlation study between the pre- and postoperative FSU angle suggested that smaller preoperative angle was related to smaller final segmental angle (Spearman $r=0.352$, $P=.078)$. 
On the other hand, global angles increased with time from $14.54^{\circ} \pm 10.32^{\circ}$ to $18.36^{\circ} \pm 11.10^{\circ}$ to become more lordotic $(P=.003 ; P=.017$ after Bonferroni correction). Regarding postoperative changes in segmental angles at adjacent segments, angles increased from $2.60^{\circ} \pm 3.04^{\circ}$ to $3.40^{\circ} \pm$ $4.11^{\circ}(P=.272)$ at upper segments and from $5.19^{\circ} \pm 3.13^{\circ}$ to $5.91^{\circ} \pm 3.53^{\circ}(P=.394)$ at lower segments, but without statistical significance (Table 1).

Mean FSU ROM decreased from $6.96^{\circ} \pm 2.03^{\circ}$ to $6.60^{\circ} \pm 2.18^{\circ}$ at 1 month postoperatively, and then increased significantly to $8.93^{\circ} \pm 3.53^{\circ}(P=.014 ; P=.0312$ after Bonferroni correction $)$ at final follow-up (Table 2). With regard to the time course of ROM changes at non-treated adjacent segments, ROMs at upper and lower segments did not change significantly, ie, from $7.95^{\circ} \pm 3.51^{\circ}$ to $8.25^{\circ} \pm 2.74^{\circ}(P=.699)$ and from $5.07^{\circ} \pm 2.56^{\circ}$ to $5.71^{\circ} \pm 2.46^{\circ}(P=.458)$, respectively. At one month postoperatively, global ROMs decreased from $40.25^{\circ} \pm$ $13.51^{\circ}$ to $31.20^{\circ} \pm 10.24^{\circ}(P=.001, P=.003$ after Bonferroni correction), but increased to the preoperative level at final follow-up (Figure 3). FSU heights showed no preoperative to postoperative change $(3.51 \pm 0.21$ to $3.49 \pm 0.22$ at final follow-up, $P=.701$ ) (Table 3 ).

Among the variables examined, only the age factor appeared to be related to postoperative FSU ROM with statistical

\section{Figure 2.}
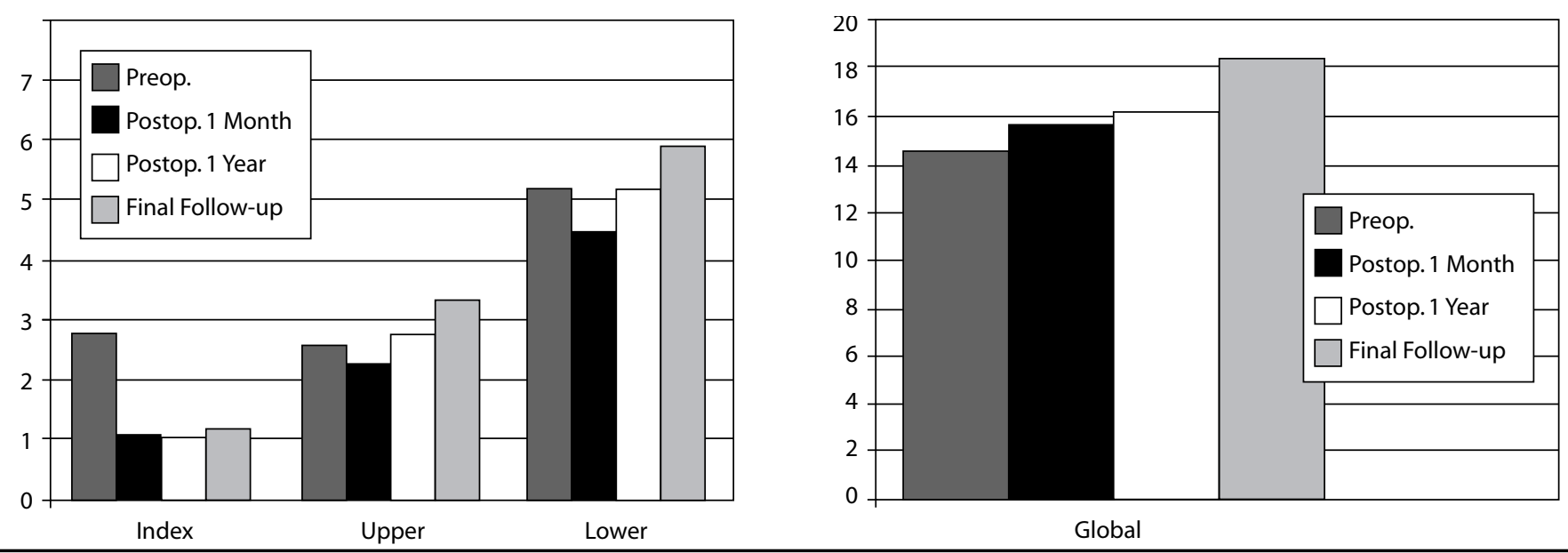

Bar graphs showing time course of angular alignment before and after Bryan disc arthroplasty.

\section{Figure 3.}
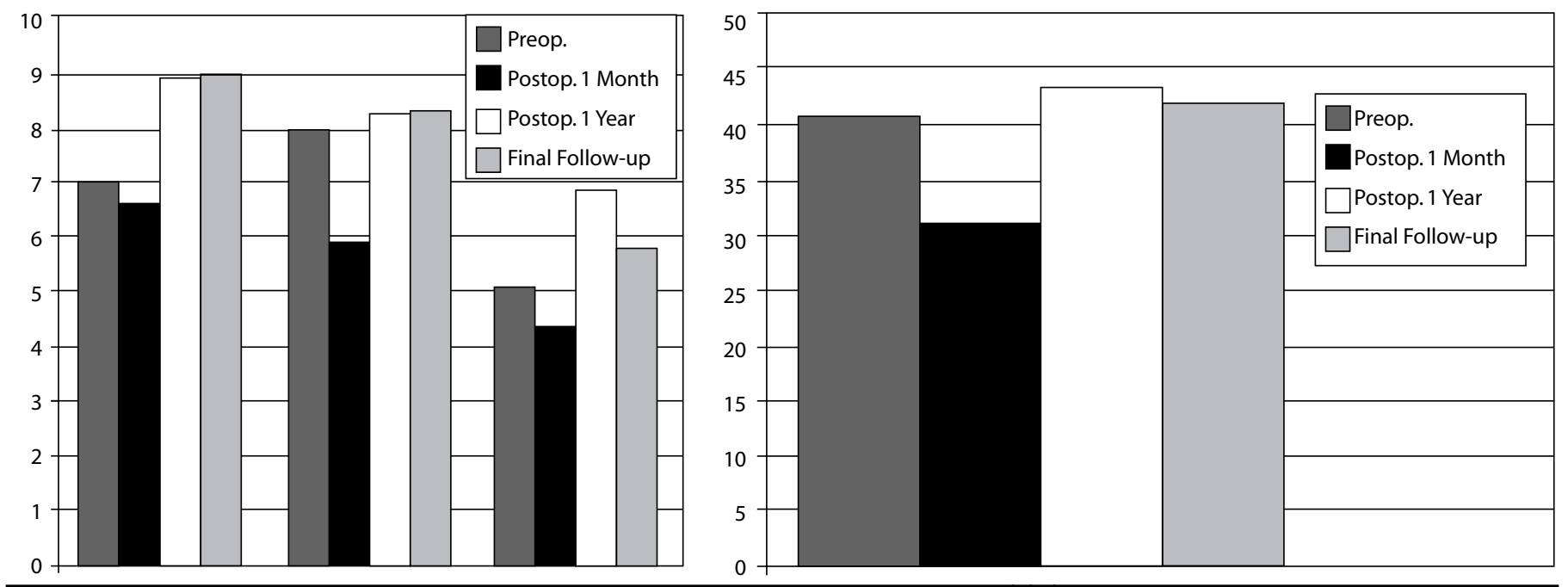

Bar graphs showing time course of ROM changes after Bryan disc arthroplasty. 
Table 1. Time Course of Angular Alignments Before and After Bryan Disc Arthroplasty

\begin{tabular}{lccccc|ccc}
\hline & \multicolumn{2}{c}{ FSU } & \multicolumn{2}{c}{ Upper Adjacent } & \multicolumn{2}{c}{ Lower Adjacent } & \multicolumn{1}{c}{ Global } \\
\hline & Angle & P-value & Angle & P-value & Angle & P-value & Angle & P-value \\
\hline Preop & $2.85 \pm 3.27$ & - & $2.60 \pm 3.04$ & - & $5.19 \pm 3.13$ & - & $14.54 \pm 10.32$ & - \\
\hline $\begin{array}{l}\text { Postop } \\
\text { 1 month }\end{array}$ & $1.03 \pm 5.74$ & .012 & $2.33 \pm 3.61$ & .606 & $4.48 \pm 3.50$ & .363 & $15.70 \pm 10.57$ & .398 \\
\hline $\begin{array}{l}\text { Postop } \\
\text { 1 year }\end{array}$ & $1.01 \pm 5.72$ & .092 & $2.79 \pm 3.88$ & .652 & $5.19 \pm 3.62$ & .777 & $16.13 \pm 9.94$ & .076 \\
\hline Final Follow-up & $1.21 \pm 5.93$ & .126 & $3.40 \pm 4.11$ & .272 & $5.91 \pm 3.53$ & .394 & $18.36 \pm 11.10$ & $.003^{*}$ \\
\hline
\end{tabular}

Table 2. Time Course of Changes in Range of Motion Before and After Bryan Disc Arthroplasty

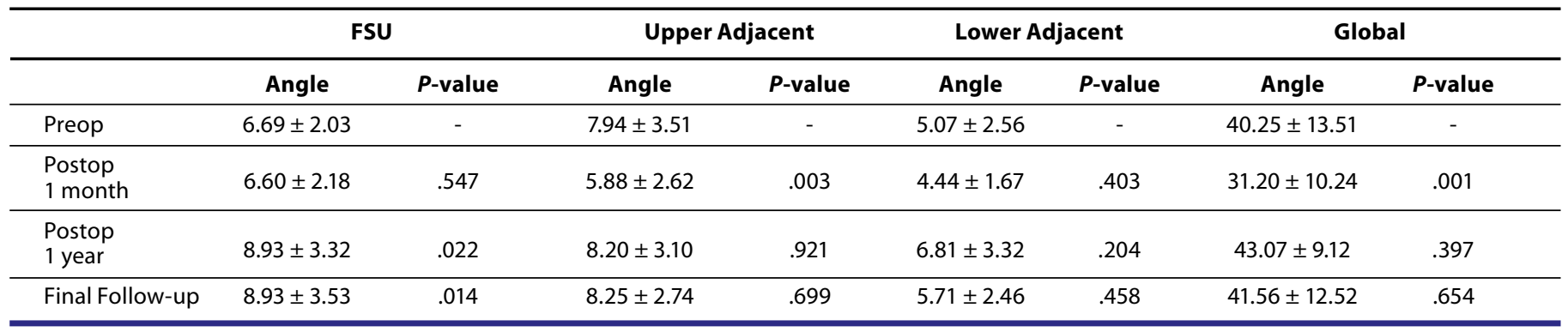

significance. The postoperative FSU ROM decreased as patients' age increased. The gender and preoperative segmental ROM did not relate to FSU ROM (Table 4).

There was no statistically significant relationship between the extent of improvement in VAS or NDI score at the last followup and postoperative FSU ROM. (Spearman $r=-0.036$, $0.074 ; P=.860, .718$, respectively).

\section{DISCUSSION}

Since the 1960s, various clinical experiences with cervical disc arthroplasty have been published, and recently, several motionpreserving cervical prostheses have become commercially available. The Bryan cervical disc was developed in the early $1990 \mathrm{~s},{ }^{8}$ and its clinical use was first described by Goffin et al. ${ }^{7}$ This cervical disc is a single-piece, metal-on-polymer prosthesis comprised of a polycarbonate/polyurethane core between two porous coated endplate shells, all encapsulated by a polymer sheath. It is a bi-articulating, unconstrained device with a fully variable, instantaneous axis of rotation.

The early clinical reports of this disc prosthesis were encouraging. Goffin et al. ${ }^{7}$ described the preliminary clinical results of 60 patients who underwent cervical arthroplasty using this disc. According to their results, relief of preoperative symptoms was observed in $86 \%$ at 6 months postimplantation without measurable device subsidence. Duggal et al. ${ }^{9}$ assessed early clinical outcomes for 30 Bryan disc prostheses in 26 patients using the physical component scores (PCS) of the short-form health survey SF-36 and NDI scores. They reported a statistically significant improvement in mean NDI scores (from 18.7 to 4.7) and in SF-36 PCS scores (from 34.58 to 46.28 ), at a mean follow-up point of
12 months postoperatively. Our study also demonstrates successful clinical results. Immediately postoperatively, mean VAS and NDI scores were significantly improved, and these were maintained at the point of final follow-up.

Several studies have discussed the radiological outcomes following insertion of the Bryan disc prosthesis. Pickett et al. ${ }^{10}$ noted that motion was preserved in operated spinal segments up to 24 months following arthroplasty in 20 patients who underwent single or 2-level implantation. Mean postoperative ROM at the index level was $8.04^{\circ}$ during early follow-up and $8.92^{\circ}$ during late follow-up, which were not significantly different from the preoperative value of $8.89^{\circ}$. Duggal et al. ${ }^{9}$ reported that mean postoperative $\mathrm{ROM}$ at the index level was $7.8^{\circ}$ at late follow-up time points, which was not significantly different from the preoperative mean value of $10.1^{\circ}$. Shim et al. ${ }^{11}$ stated that average ROM increased significantly after surgery $\left(6.7^{\circ}\right.$ to $\left.8.5^{\circ}\right)$ in 61 patients, and Fong et al. ${ }^{12}$ noted that the preoperative average ROM at index segments increased postoperatively (from $7^{\circ}$ to $8^{\circ}$ ). These studies confirm that motion preservation can be achieved and maintained.

In the present study, FSU ROM at index segments also showed increases in segmental motion, from $6.96^{\circ}$ to $8.93^{\circ}$ at the point of final follow-up. These studies revealed that the age of the patients and the preoperative segmental ROM are valuable parameters for predicting postoperative FSU ROM, although these factors do not relate to the clinical outcome. As the age of the patient increased, cervical spondylosis including disc degeneration and facet arthrosis also were advanced, which contributed to decreased segmental motion. Results of these studies indicate that preoperative segmental motion is an important prognostic factor for cervical disc replacement 
Table 3. Time Course of Changes in FSU Height Before and After Bryan Disc Arthroplasty

\begin{tabular}{|lcc|}
\hline & FSU height & $P$-value \\
\hline Preop & $3.51 \pm 0.21$ & - \\
\hline Postop 1 month & $3.50 \pm 0.22$ & .894 \\
\hline Postop 1 year & $3.51 \pm 0.20$ & .701 \\
\hline Final F/U & $3.49 \pm 0.22$ & .701 \\
\hline
\end{tabular}

Table 4. Correlation Between Postoperative FSU ROM and Clinical Variables

\begin{tabular}{|llc|}
\hline Variables & Statistical method & Results \\
\hline Gender & Independent T-test & $P=.861$ \\
\hline Age & Spearman correlation & $\begin{array}{c}\text { Coefficient }=0.391, \\
P=.048\end{array}$ \\
\hline Preoperative ROM & Spearman correlation & $\begin{array}{c}\text { Coefficient }=0.294, \\
\end{array}$ \\
& & $P=.145$ \\
\hline
\end{tabular}

in terms of motion preservation. If the segmental ROM is compromised preoperatively, arthroplasty would not be a very good option from the perspective of motion-preserving surgery.

Although contrary reports also exist, ${ }^{7,9,13}$ sagittal malalignment of the cervical spine has been mentioned after Bryan disc prostheses placement. ${ }^{11,12,14,15}$ Pickett et al. ${ }^{10}$ noted a postoperative segmental kyphosis. According to their results, a reduced segmental angle was observed in $49 \%$ of 94 operated segments. Shim et al. ${ }^{11}$ reported radiological results at an average follow-up of 6 months after Bryan cervical arthroplasty in 61 patients. It was found that mean segmental angles became more kyphotic after surgery (from $\square 0.7^{\circ}$ of kyphosis to $\square 1.3^{\circ}$ ), but without statistical significance. Johnson et al.16 also alluded to similar segmental kyphosis, which demonstrated a loss of overall lordosis of 2.7 degrees. In our study, mean FSU angle decreased from $2.85^{\circ} \pm 3.27^{\circ}$ to $1.03^{\circ} \pm 5.74^{\circ}$ at 1 month postoperatively $(P=.012)$ with statistical significance and then was maintained at final follow-up.

Sears et al. ${ }^{13}$ recently suggested that the occurrence of segmental kyphosis after Bryan cervical arthroplasty tends to depend on surgical technique. Possible factors that contribute to the development segmental kyphosis include amount of bone removal, angle of prosthesis insertion, prosthesis length, and loss of preoperative disc space height. Among these, the loss of preoperative disc space height is the most reliable predictive factor.

Loss of disc height depends on the amount of bone removed from the anterior aspect of superior vertebra and the amount of distraction achieved with the sagittal wedge. Although disc heights at index segments showed no statistically significant changes at the point of final follow-up in the present study, Fong et al. ${ }^{12}$ postulated that the milling procedure used to fit for the Bryan disc prosthesis might have a basic problem. The milling trajectory should follow the line perpendicular to the tangent drawn along the posterior cortices of the adjacent rostral and caudal vertebrae. However, in the majority of patients, the normal disc angle is not perpendicular to the posterior tangent line, which results in asymmetric endplate milling. In our opinion, kyphotic malalignment could be mainly related to excessive preparation of endplates during the milling procedure. Excessive milling and asymmetric milling of endplates result in inaccurate implantation and sequential subsidence of the treated level and segmental kyphosis. Accordingly, in order to reduce these problems, the milling procedure must be approached carefully.

In the present study, despite decreases in FSU angles, preoperative global angles increased significantly at final follow-up. This may have been caused by a compensatory increase in the lordotic angles of upper and lower nontreated segments. Mean global ROM was lower at 1 month postoperatively, but almost reached the preoperative level at final follow-up. According to Pickett et al., ${ }^{10}$ global ROM increased from a preoperative mean of $47.2^{\circ}$ to $56.1^{\circ}$ during late follow-up. They speculated that relief of neck pain during late follow-up allowed for increased neck movement in patients who had been symptomatic before surgery. In the present study, range of motion changes in upper and lower adjacent segments were minimal, which means that cervical arthroplasty with prostheses like the Bryan disc could minimize mechanical stress to adjacent levels. However, comparison studies with ACDF will be necessary to definitively determine the advantages of cervical disc arthroplasty.

\section{CONCLUSIONS}

Our results demonstrate that cervical arthroplasty with the Bryan disc for the treatment of cervical degenerative diseases can be clinically successful. Disc replacement also preserved motion postoperatively. The less preoperative segmental ROM is related to the less postoperative FSU ROM. And FSU ROM decreased as the age of the patients increased. However, these variables do not relate to the clinical outcome. The relationships between long-term outcome and these variables should be verified by a larger cohort study.

This manuscript was submitted on October 4, 2007, and accepted for publication March 24, 2008.

\section{REFERENCES}

1. Baba H, Furusawa N, Imura S, Kawahara N, Tsuchiya H, Tomita K. Late radiographic findings after anterior cervical fusion for spondylotic myeloradiculopathy. Spine. 1993;18(15):2167-2173.

2. Eck JC, Humphreys SC, Lim TH, Jeong ST, Kim JG, Hodges SD, An HS. Biomechanical study on the effect of cervical spine fusion on adjacentlevel intradiscal pressure and segmental motion. Spine. 2002;27(22):24312434.

3. Hilibrand AS, Carlson GD, Palumbo MA, Jones PK, Bohlman HH. Radiculopathy and myelopathy at segments adjacent to the site of a previous anterior cervical arthrodesis. J Bone Joint Surg Am. 
1999;81(4):519-528.

4. Matsunaga S, Kabayama S, Yamamoto T, Yone K, Sakou T, Nakanishi K. Strain on intervertebral discs after anterior cervical decompression and fusion. Spine. 1999;24(7):670-675.

5. Wigfield C, Gill S, Nelson R, Langdon I, Metcalf N, Robertson J. Influence of an artificial cervical joint compared with fusion on adjacentlevel motion in the treatment of degenerative cervical disc disease. $J$ Neurosurg. 2002;96(1 Suppl):17-21.

6. Axelsson P, Johnsson R, Stromqvist B. The spondylolytic vertebra and its adjacent segment. Mobility measured before and after posterolateral fusion. Spine. 1997;22(4):414-417.

7. Goffin J, Casey A, Kehr P, Liebig K, et al. Preliminary clinical experience with the Bryan Cervical Disc Prosthesis. Neurosurgery. 2002;51(3):840845; discussion 845-847.

8. Le H, Thongtrangan I, Kim DH. Historical review of cervical arthroplasty. Neurosurg Focus. 2004;17(3):E1.

9. Duggal N, Pickett GE, Mitsis DK, Keller JL. Early clinical and biomechanical results following cervical arthroplasty. Neurosurg Focus. 2004;17(3):E9.

10. Pickett GE, Rouleau JP, Duggal N. Kinematic analysis of the cervical spine following implantation of an artificial cervical disc. Spine. 2005;30(17):1949-1954.

11. Shim CS, Lee SH, Park HJ, Kang HS, Hwang JH. Early clinical and radiologic outcomes of cervical arthroplasty with Bryan Cervical Disc prosthesis. J Spinal Disord Tech. 2006;19(7):465-470.

12. Fong SY, DuPlessis SJ, Casha S, Hurlbert RJ. Design limitations of Bryan disc arthroplasty. Spine J. 2006;6(3):233-241.

13. Goffin J, Van Calenbergh F, van Loon J, et al. Intermediate follow-up after treatment of degenerative disc disease with the Bryan Cervical Disc Prosthesis: single-level and bi-level. Spine. 2003;28(24):2673-2678.

14. Sears WR, Duggal N, Sekhon LH, Williamson OD. Segmental malalignment with the Bryan cervical disc prosthesis - contributing factors. J Spinal Disord Tech. 2007;20(2):111-117.

15. Sears WR, Sekhon LH, Duggal N, Williamson OD. Segmental malalignment with the Bryan Cervical Disc prosthesis-does it occur? $J$ Spinal Disord Tech. 2007;20(1):1-6.

16. Johnson JP, Lauryssen C, Cambron HO, Pashman R, Regan JJ, Anand N, Bray R. Sagittal alignment and the Bryan cervical artificial disc. Neurosurg Focus. 2004;17(6):E14. 